\title{
Predominance of SARS-CoV-2 P.1 (Gamma) lineage inducing the recent wave in southern Brazil and the finding of an additional S: D614A mutation
}

Meriane Demoliner ( $\square$ merianedemoliner@gmail.com )

Universidade Feevale https://orcid.org/0000-0002-7160-7649

Mariana Soares da Silva

Universidade Feevale

Juliana Schons Gularte

Universidade Feevale

Alana Witt Hansen

Universidade Feevale

Paula Rodrigues de Almeida

Universidade Feevale

Matheus Nunes Weber

Universidade Feevale

Fágner Henrique Heldt

Universidade Feevale

Flávio Silveira

Universidade Feevale

Micheli Filippi

Universidade Feevale

Vyctoria Malayhka de Abreu Góes Pereira

Universidade Feevale

Francini Pereira da Silva

Universidade Feevale

Larissa Mallmann

Universidade Feevale

Pietra Fink

Universidade Feevale

Andréia Rosane de Moura Valim

Universidade de Santa Cruz do Sul

Lia Gonçalves Possuelo

Universidade de Santa Cruz do Sul

Juliane Deise Fleck 
Universidade Feevale

Fernando Rosado Spilki

Universidade Feevale

\section{Research Article}

Keywords: health crisis, COVID-19, B.1.1.25, Zeta lineage

Posted Date: July 21st, 2021

DOI: https://doi.org/10.21203/rs.3.rs-737320/v1

License: (c) (1) This work is licensed under a Creative Commons Attribution 4.0 International License. Read Full License 


\section{Abstract}

Since the first SARS-CoV-2 case in China in late 2019, this virus continues to impact many countries worldwide. Recently, the highest wave of SARS-CoV-2 epidemic was registered in Rio Grande do Sul (RS) State, Southern Brazil, considering the number of cases, deaths and hospitalization per day caused by COVID-19. In this study we described which lineages were circulating in the beginning of 2021 in southern Brazil to understand the cause of the highest health crisis caused by SARS-CoV-2 in the region, searching also possible additional SARS-CoV-2 sequence mutation. A total of 71 positive SARS-CoV-2 samples collected between December 15th, 2020, until April 23rd, 2021, were selected to sequencing. The samples were from 16 cities distributed in three RS regions. The library preparation was performed according to QIAseq ${ }^{\circledR}$ SARS-CoV-2 Primer Panel Handbook kit, and phylogenetic analysis was realized. Whole genome sequencing of 71 SARS-CoV-2 samples shows a predominance of Gamma lineage $(67.14 \%, 47 / 71)$, followed by Zeta lineage (27.14\%, 20/71) and B.1.1.28 (5,71\%, 4/71). Two Gamma lineage consensus sequences presented a D614A mutation. Newly mutations could be emerging due the quick SARS-CoV-2 spreading. Thus, the greater understanding about immune protection and variants vigilance is essential to the better management of the health SARS-CoV-2 crisis.

\section{Introduction}

Since the first COVID-19 case identified, in China, in late 2019 (Jin et al., 2020), SARS-CoV-2 continues to impact many countries. Globally, until early July 2021 approximately 182 million of COVID-19 cases were confirmed, including almost 4 million of deaths. During the same period, Brazil registered more than 18 million of confirmed cases and more than 500 thousand deaths caused by SARS-CoV-2 (https://covid19.who.int/). Rio Grande do Sul State (RS), Southern Brazil, has a territorial extension of $281,730.2 \mathrm{~km}^{2}$. It borders the Santa Catarina Brazil State and the countries Argentina and Uruguay. The state includes 497 municipalities, and it has approximately 11.5 million inhabitants (Fig. 1) (IBGE, 2020). The first confirmed case of COVID-19 in RS was on March 10 (SES, 2020), almost a month after the first case in Brazil, that occurred in the São Paulo State on February 25, 2020 (Rodriguez-Morales et al., 2020). Recently, the state registered its bigger SARS- CoV-2 wave reaching 13,723 cases and 342 deaths per day, also showing the highest rate of hospitalization caused by COVID-19 (Fig. 2).

In Brazil, the initially dominant lineages were B.1.1.28 and B.1.1.33 (Candido et al., 2020). In late 2020 two relevant variants arose independently, the P.1 lineage (Gamma) from Manaus and P.2 lineage (Zeta) from Rio de Janeiro. Both lineages exhibit the E484K mutation and descendant of the B.1.1.28 strain (Faria et al., 2021; Voloch et al., 2021). Over time, the zeta lineage was almost completely replaced by Gamma (Almeida et al., 2021; Barbosa et al., 2021). The starting Gamma emergence in Brazil has been estimated around November 15,2020, and it was observed that the lineage characteristics could be different from ancestral (Faria et al., 2021). Shortly thereafter, it was suggested that the Gamma is more transmissible. This fact in addition to the lack of efficient social distancing and other prevention measures probably caused the high hospitalizations (Naveca et al., 2021). Also, it was observed rapid 
dissemination to other Brazilian regions as in Southern of Brazil where the Gamma variant would have already been identified, on November 30 (Silva et al., 2021)

This same phenomenon, characterized by a rapid spread had already been observed prior to March 2020 . Lineages with D614G Spike mutation spread quickly and become predominant worldwide, starting in Europe, followed by North America and Oceania, and then Asia (Korber et al., 2020). Since few mutations can change virus fitness, the aim of this research was to investigate the lineages that were circulating in the beginning of 2021 in southern Brazil, to better understand the possible virus-related causes of the major health crisis caused by SARS-CoV-2 in the region, searching also possible additional SARS-COV-2 mutations.

\section{Material And Methods \\ 2.1. Sampling}

A total of 70 positive samples to SARS-COV-2, collected between December 15th, 2020 until April 23rd, 2021, were selected to high throughput sequencing. The RT-qPCR screening was performed targeting the E gene, according to Charité (Corman et al., 2020). The samples were from 16 cities distributed in three RS regions (Metropolitan Porto Alegre, North East and Eastern center) (Fig. 1). The sampling is characterized by 42 males and 28 females, with ages ranging from 10 to 86 years old.

\subsection{SARS-COV-2 Library preparation}

Total RNA was extracted from nasopharyngeal swabs using commercial MagMAX ${ }^{\mathrm{TM}}$ CORE Nucleic Acid

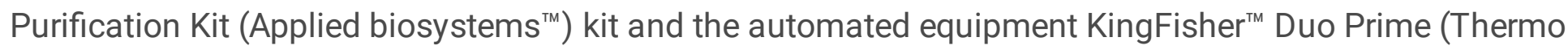
Fisher Scientific $\left.{ }^{\mathrm{TM}}\right)$. After, reverse transcriptase reaction was achieved using SuperScript IV kit and the library preparation was performed according to QIAseq ${ }^{\circledR}$ SARS-CoV-2 Primer Panel Handbook kit. The sequencing occurred on an Illumina MiSeq platform using MiSeq Reagent Kit v3 (600-cycle).

\subsection{Phylogenetics analysis}

FASTQ reads were trimmed (BBDuk 37.25) and mapped against the reference sequence hCoV19/Wuhan/WIV04/2019 (EPI_ISL_402124) available in EpiCoV database from GISAID (https://www.gisaid.org/ 45) using Geneious Prime software. Sequence alignment was performed using Clustal Omega and the reference sequence from Wuhan was applied as an outgroup. The Maximum Likelihood phylogenetic analysis under the General Time Reversible model allowing for a proportion of invariable sites and substitution rates were inferred empirically in IQ-TREE v2.1.2 webserver (Nguyen et al., 2015) applying 200 replicates and 1000 bootstrap.

\section{Results}

Complete genome analysis of 70 SARS-CoV-2 samples shows a predominance of Gamma lineage (67.14 $\%, 47 / 70)$, followed by Zeta lineage $(27.14 \%, 19 / 70)$ and B.1.1.28 $(5.71 \%, 4 / 70)$ (Fig. 3). The Gamma 
sequences generated herein presented the classical mutational signatures in spike glycoprotein L18F, T20N, P26S, D138Y, R190S, K417T, E484K, N501Y, D614G, H655Y, T1027I and V1176F, with some exceptions, as in the sample hCoV-19/Brazil/LMM53965 and hCoV-19/Brazil/LMM54004 that change a guanine for an adenine in 614 position (D614G $\rightarrow$ D614A) and the hCoV-19/Brazil/LMM54029 that change a histidine for a glutamic acid in 655 position ( $\mathrm{H} 655 \mathrm{Y} \rightarrow \mathrm{H} 655 \mathrm{E}$ ). Zeta sequences presented E484K, D614G e V1176F and the B.1.1.28 sequences, D614G and V1176F spike mutations. The distribution rate of lineages by period were the following 2021/01/28-02/28: $14.81 \%$ of B.1.1.28, 37.04 of Gamma and 48.15\% of Zeta; 2021/03/01-03/23: none B.1.1.28, 25\% of Zeta and $75 \%$ of Gamma; 2021/04/08-04/23: none B.1.1.28, 11.43\% of Zeta and $88.57 \%$ of Gamma (Fig. 4).

\section{Discussion}

The phylogenetic analysis from samples between January 28, 2021, to April 23 period showed that the majority of the sequences belong to Gamma lineage. Zeta lineage presented a medium frequency and the B.1.1.28 lineage in a lower frequency (Fig. 3). At the beginning of 2021, the fast Gamma lineage spread, and dominance were also seen in other Brazilian States. In São Paulo State on March 2021, the Gamma variant was observed in a higher frequency, where the detection rates were $78.6 \%$ (first week) and $91.7 \%$ (second week). At the same time, other variants as Zeta, B.1.1.7 and B.1.1.28 presented a low frequency (Barbosa et al., 2021). In the RJ state a fast replacement of Zeta by Gamma lineage was observed between 24 and 28 of March 2021 (Almeida et al., 2021). In March and April, this happened here, the Gamma lineage representing $75 \%$ and $88.57 \%$ of all sequences, respectively.

Between the end of January until the end of February 2021 our results showed the presence of Gamma and Zeta lineages in the approximate proportion rate. However, in March, the Zeta lineage represented only a third of sequences and, in April, a higher prevalence of Gamma lineage was identified. This scenario was concomitant with the increase in the numbers of cases $(13,723)$, deaths $(342)$, and hospitalization per day (5435 in clinical hospital beds and 2634 in ICU) caused by COVID-19. Those numbers marked the highest SARS- CoV-2 epidemic wave during the pandemic in this region (date observed until July 2021) (Fig. 2). It has already been described that Gamma lineage can escape of the neutralization antibodies acquired by infection or immunization with previously circulating viral variants (de Souza et al., 2021). As well, it was suggested that the Gamma is more transmissible than previously circulating lineages (Naveca et al., 2021). These facts, in addition to the lack an efficient social distancing and other prevention measures probably caused the high numbers observed in this big SARS- CoV-2 wave.

In this research, two genomes presented the change of a guanine for an adenine in 614 position, the D614G mutation. The D614G is a relevant Spike mutation observed in early March 2020 (Korber et al., 2020). This mutation presents high viral viability probably attributable to minuscule changes in partitioning energy (Laha et al., 2020). Prior to March, the D614G was present in 10\% of global sequences, from 1 st to March 31, 2020, the detection rate already reached $67 \%$ of sequences and, from 
1st April to May 18, 2020, the D614G mutations have already been observed in $78 \%$ of the sequences (Korber et al., 2020).

This rapid spread and dominancy of sequences with D614G mutation globally, probably is related with the advantage observed in replication efficiency when comparing to D614, which can increase the probability of human-to-human transmission (Plante et al., 2021; Yurkovetskiy et al., 2020). The D614G for D614A change has already been identified in July 2020 in three individuals who returning to Korea from Uzbekistan (Park et al., 2020). Nevertheless, the less frequency of DG614A mutation may be related to lower transmission efficiency or less adaptation in the environment. This change doesn't a worrying mutation, however, it is a warning to continue monitoring new mutations in the SARS-CoV-2 genome.

Evolutionary theory predicts that viruses mutations may be selectively neutral or advantageous to viral fitness (Volz et al., 2021). In SARS-CoV-2 some mutations were correlated with advantages, as the increase of rate of transmission (example: D614G mutation and Gamma variant) and decrease neutralizing antibodies. For example Spike protein has NTD and RBD regions that induce specific antibodies with neutralizing activity (Yang \& Du, 2021) Consequences on antibody neutralization already were observed in variants as the B.1.1.7, B.1.351 and Gamma, that present RBD region mutation (K417N, E484K and N501Y). In addition, the reducing in neutralizing was observed in variants with mutations in NTD region and convalescent plasma. Although the results could not necessarily equivalent to natural infection and transmission, these mutations probably cause advantage to the virus (Wang et al., 2021). Spike amino acid substitutions and deletions affect antibody neutralization, and these changes are present at significant frequencies in the global virus population (Harvey et al., 2021).

\section{Conclusion}

Mutations may increase the advantage for the viral transmissibility and escape from neutralizing antibodies. In Brazil, there are still many SARS-CoV-2 cases per day and low vaccination coverage. Thus, mutations might be emerging because of the quick spreading of SARS-CoV-2, and a greater understanding of immune protection and variants vigilance is essential to the better management of the health crisis caused by SARS-CoV-2.

\section{Declarations}

\section{Ethics declarations}

Project approved by the Research Ethics Committee (CEP) at Feevale University. Process number: CAAE: 33202820.7.1001.5348.

Acknowledgments 
This work is an initiative of RedeCorona-ômica BR MCTI/FINEP affiliated to RedeVírus/MCTI (FINEP = 01.20.0029.000462/20, CNPq $=404096 / 2020-4)$. The authors also are grateful for the financial CAPES, CNPq ad Research Support Foundation of the State of Rio Grande do Sul (FAPERGS). See Supplementary Acknowledgments.

Conflict of interests

The authors have no conflict of interests to declare.

\section{References}

Almeida, L. G. P. de, Lamarca, A. P., Jr, R. da S. F., Cavalcante, L., Gerber, A. L., Guimarães, A. P. de C., Machado, D. T., Alves, C., Mariani, D., Cruz, T. F., Ribeiro, M. S., Carvalho, S., Silva, F. D. da, Garcia, M. H. de O., Souza, L. M. de, Silva, C. G. Da, Ribeiro, C. L. P., Cavalcanti5, A. C., Mello, C. M. B. de, ... Vasconcelos, A. T. R. 2021. Genomic Surveillance of SARS-CoV-2 in the State of Rio de Janeiro, Brazil: technical briefing. Virological. https://virological.org/t/genomic-surveillance-of-sars-cov-2-in-the-state-of-rio-de-janeiro-braziltechnical-briefing/683

Barbosa, G. R., Moreira, L. V. L., Justo, A. F. O., Perosa, A. H., de Souza Luna, L. K., Chaves, A. P. C., Bueno, M. S., Conte, D. D., Carvalho, J. M. A., Prates, J., Dantas, P. S., Faico-Filho, K. S., Camargo, C., Resende, P. C., Siqueira, M. M., \& Bellei, N. 2021. Rapid spread and high impact of the variant of concern P.1 in the largest city of Brazil. J. Infect, 83(1), 119-145. https://doi.org/10.1016/j.jinf.2021.04.008

Candido, D. S., Claro, I. M., de Jesus, J. G., Souza, W. M., Moreira, F. R. R., Dellicour, S., Mellan, T. A., du Plessis, L., Pereira, R. H. M., Sales, F. C. S., Manuli, E. R., Thézé, J., Almeida, L., Menezes, M. T., Voloch, C. M., Fumagalli, M. J., Coletti, T. M., da Silva, C. A. M., Ramundo, M. S., ... Faria, N. R. 2020. Evolution and epidemic spread of SARS-CoV-2 in Brazil. Science, 369(6508), 1255-1260.

https://doi.org/10.1126/science.abd2161

Corman, V. M., Landt, O., Kaiser, M., Molenkamp, R., Meijer, A., Chu, D. K. W., Bleicker, T., Brünink, S., Schneider, J., Schmidt, M. L., Mulders, D. G. J. C., Haagmans, B. L., Van Der Veer, B., Van Den Brink, S., Wijsman, L., Goderski, G., Romette, J. L., Ellis, J., Zambon, M., ... Drosten, C. 2020. Detection of 2019 novel coronavirus (2019-nCoV) by real-time RT-PCR. Euro Surveill., 25(3), 1-8. https://doi.org/10.2807/15607917.ES.2020.25.3.2000045

de Souza, W. M., Amorim, M. R., Sesti-Costa, R., Coimbra, L. D., Toledo-Teixeira, D. A. de, Parise, P. L., Barbosa, P. P., Bispo-dos-Santos, K., Mofatto, L. S., Simeoni, C. L., Brunetti, N. S., Claro, I. M., Duarte, A. S. S., Coletti, T. M., Zangirolami, A. B., Costa-Lima, C., Gomes, A. B. S. P., Buscaratti, L. I., Sales, F. C., ... Proenca-Modena, J. L. 2021. Levels of SARS-CoV-2 Lineage P.1 Neutralization by Antibodies Elicited after Natural Infection and Vaccination. SSRN Electronic Journal. https://doi.org/10.2139/ssrn.3793486 
Faria, N. R., Mellan, T. A., Whittaker, C., Claro, I. M., Candido, D. da S., Mishra, S., Crispim, M. A. E., Sales, F. C. S., Hawryluk, I., McCrone, J. T., Hulswit, R. J. G., Franco, L. A. M., Ramundo, M. S., de Jesus, J. G., Andrade, P. S., Coletti, T. M., Ferreira, G. M., Silva, C. A. M., Manuli, E. R., ... Sabino, E. C. 2021. Genomics and epidemiology of the P.1 SARS-CoV-2 lineage in Manaus, Brazil. Science, 372(6544), 815-821. https://doi.org/10.1126/science.abh2644

Harvey, W. T., Carabelli, A. M., Jackson, B., Gupta, R. K., Thomson, E. C., Harrison, E. M., Ludden, C., Reeve, R., Rambaut, A., Peacock, S. J., \& Robertson, D. L. 2021. SARS-CoV-2 variants, spike mutations and immune escape. Nat. Rev. Microbiol 19(7), 409-424. https://doi.org/10.1038/s41579-021-00573-0

IBGE. 2020. Rio Grande do Sul. Rio Grande Do Sul. https://cidades.ibge.gov.br/brasil/rs/panorama (accessed 13 July 2003).

Jin, Y.-H., Cai, L., Cheng, Z.-S., Cheng, H., Deng, T., Fan, Y.-P., Fang, C., Huang, D., Huang, L.-Q., Huang, Q., Han, Y., Hu, B., Hu, F., Li, B.-H., Li, Y.-R., Liang, K., Lin, L.-K., Luo, L.-S., Ma, J., ... Wang, X.-H. 2020. A rapid advice guideline for the diagnosis and treatment of 2019 novel coronavirus (2019-nCoV) infected pneumonia (standard version). Mil. Med. Res., 7(1), 4. https://doi.org/10.1186/s40779-020-0233-6

Korber, B., Fischer, W. M., Gnanakaran, S., Yoon, H., Theiler, J., Abfalterer, W., Hengartner, N., Giorgi, E. E., Bhattacharya, T., Foley, B., Hastie, K. M., Parker, M. D., Partridge, D. G., Evans, C. M., Freeman, T. M., de Silva, T. I., McDanal, C., Perez, L. G., Tang, H., ... Wyles, M. D. 2020. Tracking Changes in SARS-CoV-2 Spike: Evidence that D614G Increases Infectivity of the COVID-19 Virus. Cell, 182(4), 812-827.e19. https://doi.org/10.1016/j.cell.2020.06.043

Laha, S., Chakraborty, J., Das, S., Manna, S. K., Biswas, S., \& Chatterjee, R. 2020. Characterizations of SARS-CoV-2 mutational profile, spike protein stability and viral transmission. Infect Genet Evol. 85, 104445. https://doi.org/10.1016/j.meegid.2020.104445

Naveca, F. G., Nascimento, V., de Souza, V. C., Corado, A. de L., Nascimento, F., Silva, G., Costa, Á., Duarte, D., Pessoa, K., Mejía, M., Brandão, M. J., Jesus, M., Gonçalves, L., da Costa, C. F., Sampaio, V., Barros, D., Silva, M., Mattos, T., Pontes, G., ... Bello, G. 2021. COVID-19 in Amazonas, Brazil, was driven by the persistence of endemic lineages and P.1 emergence. Nat. Med. https://doi.org/10.1038/s41591-02101378-7

Nguyen, L.-T., Schmidt, H. A., von Haeseler, A., \& Minh, B. Q. 2015. IQ-TREE: A Fast and Effective Stochastic Algorithm for Estimating Maximum-Likelihood Phylogenies. Mol. Biol. Evol. 32(1), 268-274. https://doi.org/10.1093/molbev/msu300

Park, A. K., No, J. S., Shin, E., Chung, Y.-S., Kim, I.-H., Kang, B.-H., Rhie, G.-E., Kim, H. M., Kim, J.-M., Park, Y. E., Kim, M. J., Park, J. S., Yoo, C.-K., \& Kim, J. 2020. Emergence of the D614A mutation in the spike protein of SARS-CoV-2: Imported cases to the South Korea. MedRxiv, 2020.09.04.20184721.

http://medrxiv.org/content/early/2020/09/07/2020.09.04.20184721.abstract 
Plante, J. A., Liu, Y., Liu, J., Xia, H., Johnson, B. A., Lokugamage, K. G., Zhang, X., Muruato, A. E., Zou, J., Fontes-Garfias, C. R., Mirchandani, D., Scharton, D., Bilello, J. P., Ku, Z., An, Z., Kalveram, B., Freiberg, A. N., Menachery, V. D., Xie, X., ... Shi, P.-Y. 2021. Spike mutation D614G alters SARS-CoV-2 fitness. Nature, 592(7852), 116-121. https://doi.org/10.1038/s41586-020-2895-3

Rodriguez-Morales, A. J., Gallego, V., Escalera-Antezana, J. P., Méndez, C. A., Zambrano, L. I., FrancoParedes, C., Suárez, J. A., Rodriguez-Enciso, H. D., Balbin-Ramon, G. J., Savio-Larriera, E., Risquez, A., \& Cimerman, S. 2020. COVID-19 in Latin America: The implications of the first confirmed case in Brazil. Travel Med Infect Dis., 35(January), 101613. https://doi.org/10.1016/j.tmaid.2020.101613

SES. (2020). Confirmado o primeiro caso de novo coronavírus no Rio Grande do Sul. https://saude.rs.gov.br/confirmado-o-primeiro-caso-de-novo-coronavirus-no-rio-grande-do-sul. (accessed 13 July 2003).

Silva, M. S. da, Demoliner, M., Hansen, A. W., Gularte, J. S., Silveira, F., Heldt, F. H., Filippi, M., Pereira, V. M. de A. G., Silva, F. P. da, Mallmann, L., Fink, P., Silva, L. L. da, Weber, M. N., Almeida, P. R. de, Fleck, J. D., \& Spilki, F. R. 2021. Early detection of SARS-CoV-2 P.1 variant in Southern Brazil and reinfection of the same patient by P.2. Inst. Med. Trop. Sao Paulo, 63. https://doi.org/10.1590/s1678-9946202163058

Voloch, C. M., da Silva Francisco, R., de Almeida, L. G. P., Cardoso, C. C., Brustolini, O. J., Gerber, A. L., Guimarães, A. P. de C., Mariani, D., da Costa, R. M., Ferreira, O. C., Cavalcanti, A. C., Frauches, T. S., de Mello, C. M. B., Leitão, I. de C., Galliez, R. M., Faffe, D. S., Castiñeiras, T. M. P. P., Tanuri, A., \& de Vasconcelos, A. T. R. 2021. Genomic Characterization of a Novel SARS-CoV-2 Lineage from Rio de Janeiro, Brazil. J Virol., 95(10). https://doi.org/10.1128/JVI.00119-21

Volz, E., Hill, V., McCrone, J. T., Price, A., Jorgensen, D., O’Toole, Á., Southgate, J., Johnson, R., Jackson, B., Nascimento, F. F., Rey, S. M., Nicholls, S. M., Colquhoun, R. M., da Silva Filipe, A., Shepherd, J., Pascall, D. J., Shah, R., Jesudason, N., Li, K., ... Neaverson, A. S. 2021. Evaluating the Effects of SARS-CoV-2 Spike Mutation D614G on Transmissibility and Pathogenicity. Cell, 184(1), 64-75.e11.

https://doi.org/10.1016/j.cell.2020.11.020

Wang, R., Zhang, Q., Ge, J., Ren, W., Zhang, R., Lan, J., Ju, B., Su, B., Yu, F., Chen, P., Liao, H., Feng, Y., Li, X., Shi, X., Zhang, Z., Zhang, F., Ding, Q., Zhang, T., Wang, X., \& Zhang, L. 2021. Analysis of SARS-CoV-2 variant mutations reveals neutralization escape mechanisms and the ability to use ACE2 receptors from additional species. Immunity. https://doi.org/10.1016/j.immuni.2021.06.003

Yang, Y., \& Du, L. 2021. SARS-CoV-2 spike protein: a key target for eliciting persistent neutralizing antibodies. Signal Transduct Target Ther, 6(1), 95. https://doi.org/10.1038/s41392-021-00523-5

Yurkovetskiy, L., Wang, X., Pascal, K. E., Tomkins-Tinch, C., Nyalile, T. P., Wang, Y., Baum, A., Diehl, W. E., Dauphin, A., Carbone, C., Veinotte, K., Egri, S. B., Schaffner, S. F., Lemieux, J. E., Munro, J. B., Rafique, A., Barve, A., Sabeti, P. C., Kyratsous, C. A., ... Luban, J. 2020. Structural and Functional Analysis of the D614G SARS-CoV-2 Spike Protein Variant. Cell, 183(3), 739-751.e8. https://doi.org/10.1016/j.cell.2020.09.032 


\section{Figures}

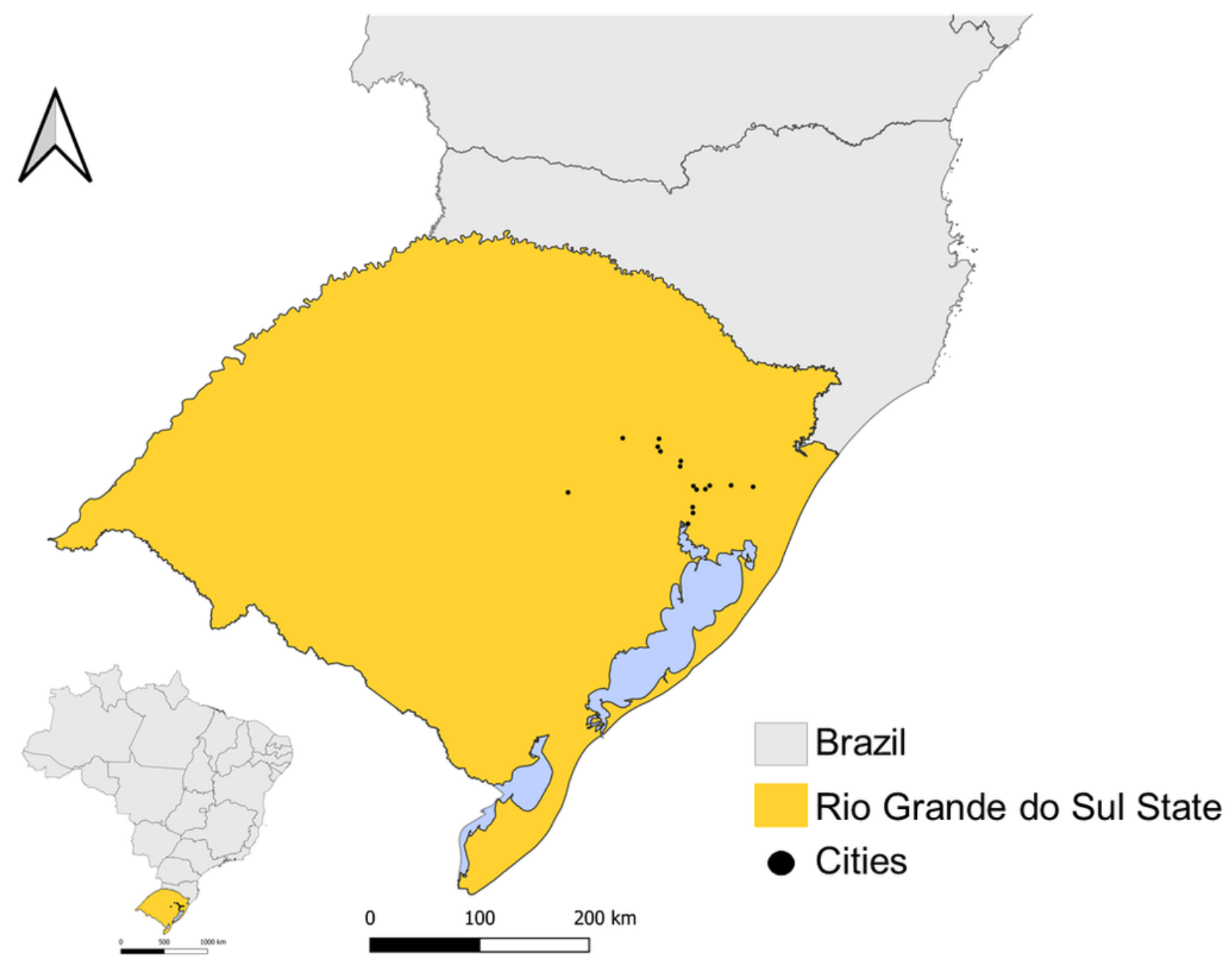

Figure 1

Rio Grande do Sul State (RS) geographic location. On the left, Brazil map (in grey) with the RS highlighted in yellow. The black dots represent the 16 cites from Metropolitan Porto Alegre, Northeast and Eastern center regions of RS. 

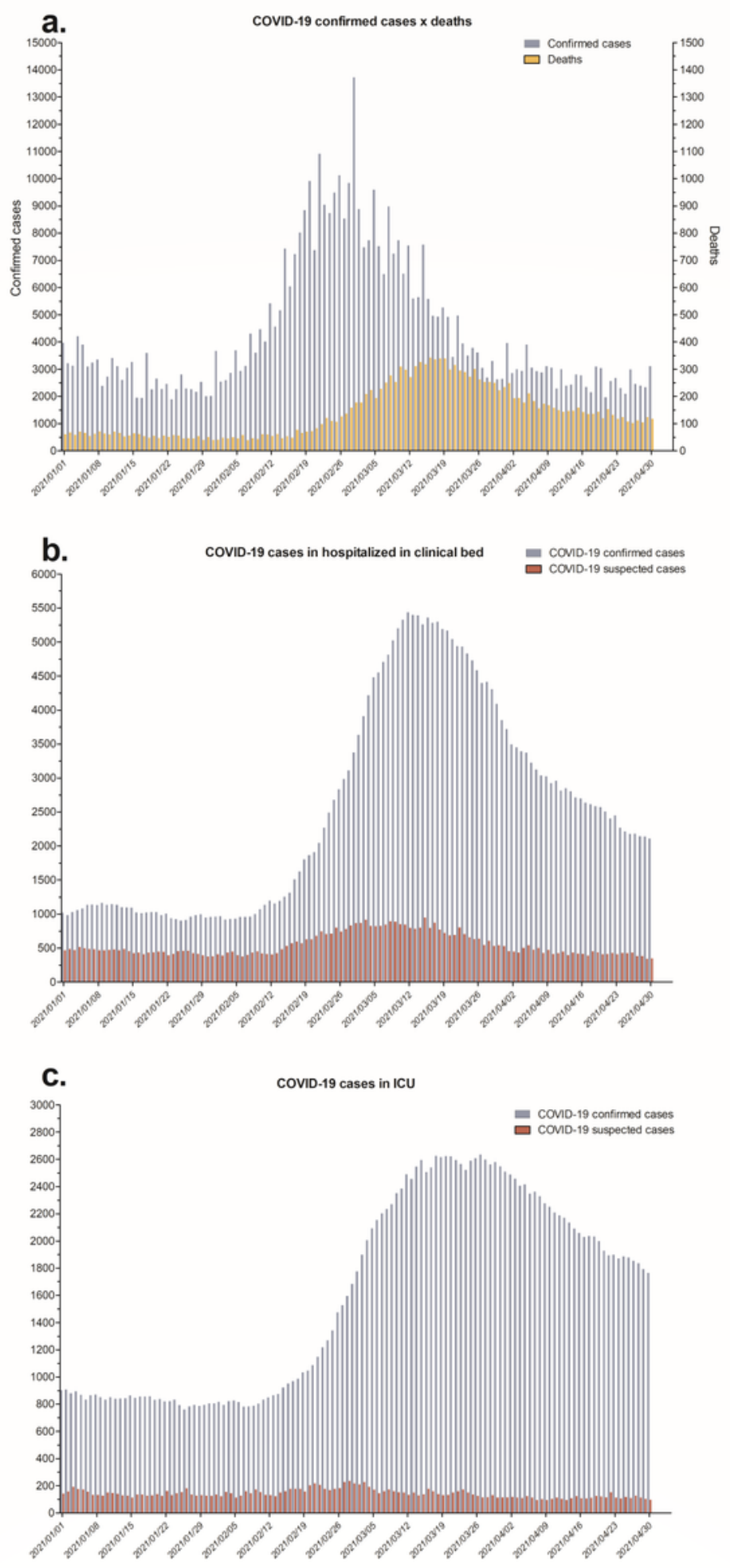

\section{Figure 2}

Rio Grande do Sul state COVID-19 general data between 2021 January and April. a) Covid-19 confirmed cases and deaths. b) COVID-19 confirmed and suspected cases in clinical bed hospitalizations. c) COVID19 confirmed and suspected cases in ICU hospitalizations. 


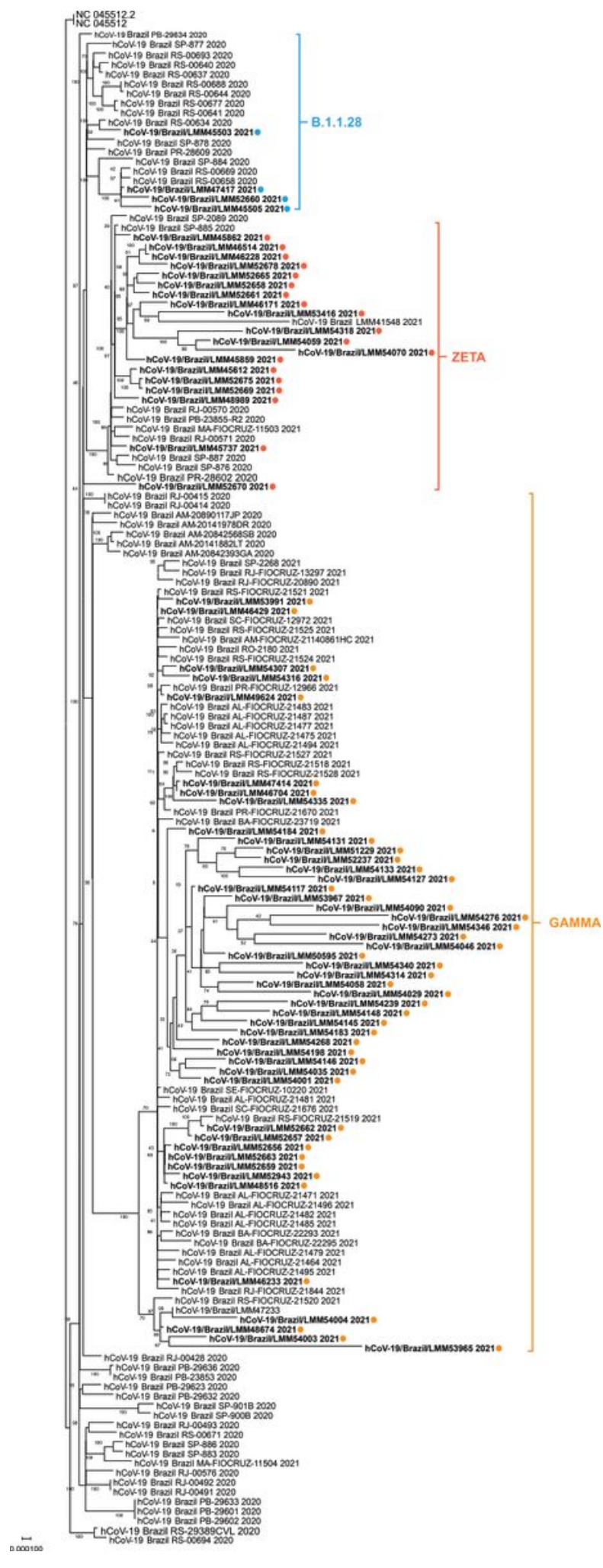

\section{Figure 3}

SARS-CoV-2 complete genome phylogenetic tree. The Maximum Likelihood phylogenetic analysis was performed in IQ-TREE v2.1.2 web server applying 200 replicates and 1000 bootstrap. The long branches observed in some sequences could be related to a lack primers annealing in some ORF1ab and ORF8 short regions. 
B.1.1.28, Zeta and Gamma distribution lineages

B.1.1.28

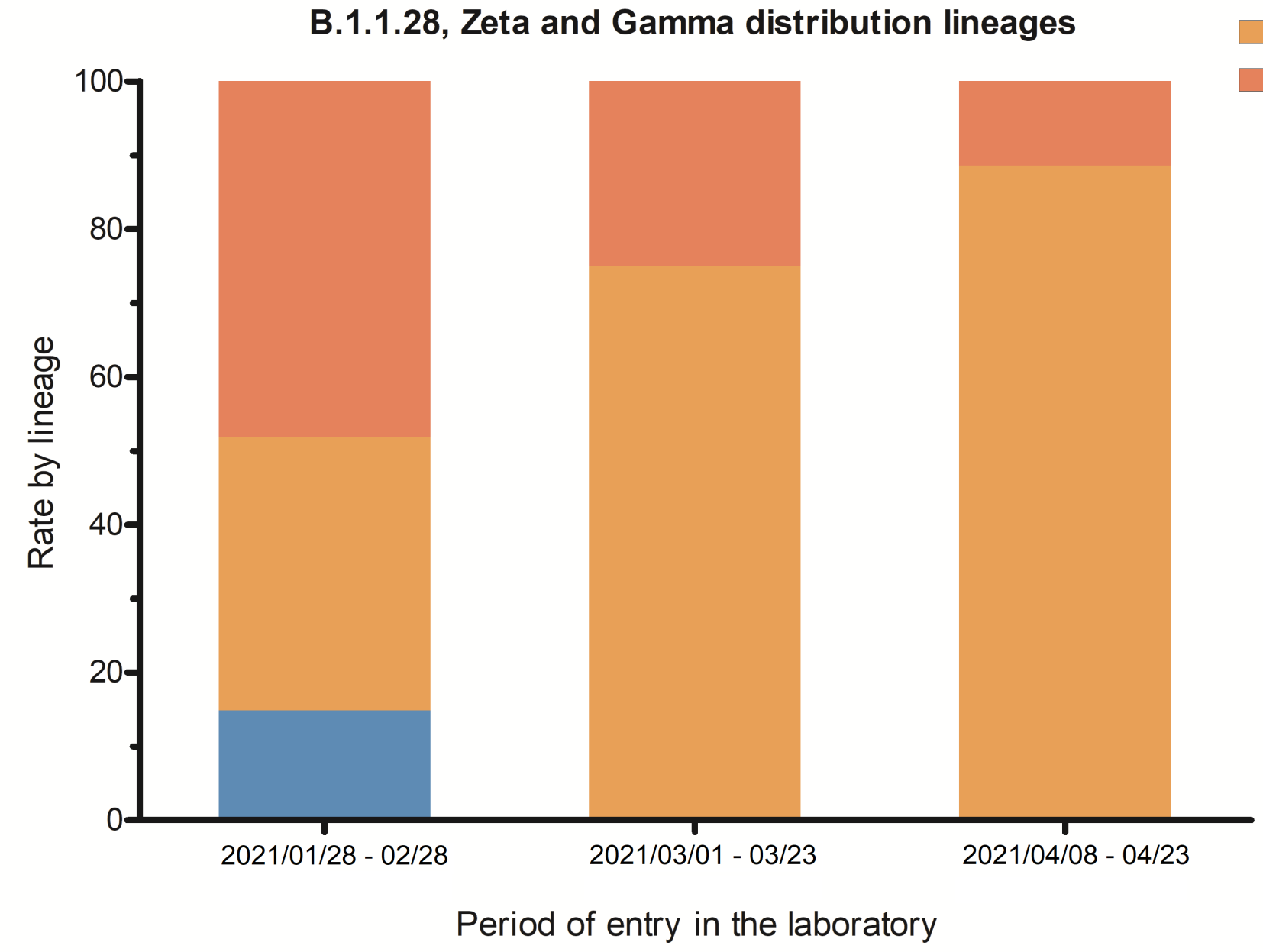

Figure 4

B.1.1.28, Zeta and Gamma distribution lineages. Lineages rate by period of entry in the Microbiology Molecular Laboratory. 